\title{
Amamentação no alojamento conjunto: percepção de mães primíparas no puerpério imediato
}

\author{
Breastfeeding in joint accommodation: \\ perception of primiparous mothers in the \\ immediate puerperium
}

\section{Aisiane Cedraz Morais ${ }^{1}$ (1) Bárbara Antonia Souza Lima ${ }^{2}$ (1) Mayane Trindade Silva ${ }^{3}$ (1) Ariane Cedraz Morais ${ }^{4}$ (1) Rita de Cássia Rocha Moreira ${ }^{5}$ (i) Caroline Barreto Freire Oliveira ${ }^{6}$ (1)}

\begin{abstract}
1'Autora para correspondência. Universidade Estadual de Feira de Santana (Feira de Santana). Bahia, Brasil. aisicedraz@hotmail.com 2-6Universidade Estadual de Feira de Santana (Feira de Santana). Bahia, Brasil. barbarete_13@hotmail.com, maayanetrindade@gmail.com, enfarianecedraz@hotmail.com, ritahelio01@yahoo.com.br, cbfoliveira2411@gmail.com
\end{abstract}

RESUMO | OBJETIVO: Compreender a percepção da puérpera primípara sobre o processo da amamentação no Alojamento Conjunto. MÉTODOS: pesquisa descritiva e exploratória com abordagem qualitativa. Foram entrevistadas cinco puérperas internadas no Alojamento Conjunto de uma maternidade pública, no interior da Bahia. Os dados foram coletados por meio de entrevista semiestruturada e analisados pela técnica de Bardin. A pesquisa foi aprovada pelo CEP/UEFS, sob o parecer $n^{\circ}$ 2.529.234. RESULTADOS: Emergiram três categorias: significados da amamentação para as mães; dificuldades da amamentação no AC; e estratégias incentivadoras para amamentação. A amamentação tem significados como: um ato de amor, prazeroso; aleitamento como promoção da saúde da criança; de seu bem estar físico e emocional, prevenção de doenças e vínculo entre mãe e filho. Ainda, a amamentação como momento de dor e resignação. CONCLUSÃo: Constatou-se a falta de orientação no prénatal, manejo inadequado da amamentação que resultou em dores e outros desconfortos físicos oriundos da pega incorreta e do mau posicionamento do bebê. Emergiu a falta de privacidade no Alojamento Conjunto. Explicitou-se algumas estratégias incentivadoras: orientações acerca das técnicas de aleitamento; atenção dos profissionais aos aspectos emocionais e ainda, o apoio da família, fundamentais para o sucesso da amamentação.

DESCRITORES: Alojamento conjunto. Aleitamento materno. Período pós-parto.

\begin{abstract}
OBJECTIVE: To understand the perception of the primiparous postpartum woman about the process of breastfeeding in rooming-in. METHODS: descriptive and exploratory research with qualitative approach. Five puerperal women hospitalized at the Joint Accommodation of a public maternity hospital in the Bahia countryside were interviewed. Data were collected through semi-structured interviews and analyzed by Bardin technique. The research was approved by UEFS Ethical Committee, under registry $n^{\circ}$ 2.529.234. RESULTS: Three categories emerged: meanings of breastfeeding for mothers; breastfeeding difficulties in J.A.; and encouraging strategies for breastfeeding. Breastfeeding has meanings such as: a pleasurable act of love; breastfeeding as a health promotion for the child; of their physical and emotional well-being, disease prevention and mother-child bonding. Still, breastfeeding as a moment of pain and resignation. CONCLUSION: We found a lack of prenatal guidance, inadequate management of breastfeeding that resulted in pain and other physical discomfort arising from incorrect handling and poor positioning of the baby. The lack of privacy in the Co-Accommodation has emerged. Some encouraging strategies were explained: guidelines on breastfeeding techniques; professionals' attention to emotional aspects and family support, which are fundamental for breastfeeding success.
\end{abstract}

KEYWORDS: Rooming-in care. Breast feeding. Postpartum period. 


\section{Introdução}

O Aleitamento Materno Exclusivo (AME), no ponto de vista nutricional, consiste no mais nutritivo e adequado alimento para a criança até os seis primeiros meses de vida, sendo ele rico em vitaminas, proteínas, carboidratos, gorduras, sais minerais e água. São esses os nutrientes essenciais para a criança. $O$ Aleitamento Materno (AM) está entre as prioridades e é considerada a estratégia que mais previne a morbimortalidade infantil além de promover a saúde física e psíquica do lactente e da mulher que amamenta'.

No que diz respeito às contribuições do aleitamento materno exclusivo, para a mãe, vão desde o retorno do útero, diminuição das chances de sangramento, consequentemente redução das chances de anemia, até um retorno mais rápido a forma física².

Portanto, para o sucesso na amamentação, é necessário um trabalho de conscientização, educação e de informação para as mães desde o pré-natal até o puerpério. Mostrando-se uma ferramenta fundamental o envolvimento dos profissionais de saúde com relação a amamentação em diferentes níveis de atenção à saúde, possibilitando envolver a gestante e, posteriormente, a mãe, assim como sua família, num processo de orientação acerca da importância da amamentação.

Dessa forma, vale ressaltar a importância deste procedimento nas primeiras horas pós parto, pois eles são determinantes para que a amamentação inicie precocemente e se estabeleça como uma prática efetiva, o que em muito contribui a Amamentação no Alojamento Conjunto, (AC) tema que foi o objeto desta pesquisa que ouviu das puérperas suas impressões sobre esta prática, antes e depois de sua ocorrência.

O Alojamento Conjunto permite que o recém-nascido permaneça com a mãe até a alta hospitalar, favorecendo a humanização, o aleitamento, a diminuição do risco de infecção hospitalar ${ }^{3}$. Foi um experimento criado por Edith Jackson visando tornar o nascimento mais humano por colocar o bebê junto à mãe, devolvendo a esta a possibilidade de cuidar do próprio filho uma vez que permanecem juntos desde o nascimento até alta, durante as 24 horas do dia, período em que a amamentação é estimulada por todos.
Portanto, tem-se como objetivo do estudo compreender a percepção da puérpera primípara sobre o processo da amamentação no AC.

\section{Metodologia}

Foi realizada uma pesquisa qualitativa, descritiva e exploratória, uma vez que a preocupação central é com o aprofundamento de questões que não podem ser mensuradas, por tratar-se das representações, das crenças das percepções e das opiniões das mães acerca fenômeno em estudo.

Essa pesquisa se desenvolveu no município de Feira de Santana, especificamente no Alojamento Conjunto do Hospital Inácia Pinto dos Santos (HIPS), com puérperas que estiveram no AC e que atendiam aos critérios de inclusão. A quantidade de entrevistadas não foi pré-determinado, sendo realizadas cinco (05) entrevistas, quantidade que possibilitou dados suficientes para compreensão do objeto de estudo.

Participaram da pesquisa, as mães que concordaram em fazer parte da mesma voluntariamente, após leitura e assinatura do Termo de Consentimento Livre e Esclarecido (TCLE).

Para a coleta de dados, foi utilizada a técnica da Entrevista Semiestruturada proposta por Bardin4. A Entrevista Semiestruturada foi feita a partir de um roteiro previamente elaborado que continha dados de identificação das entrevistadas e questões norteadoras sobre a percepção das puérperas sobre amamentação e amamentação no alojamento conjunto.

Além disso, o presente estudo respeitou os aspectos éticos adotados a partir da Resolução 466/2012 do Conselho Nacional de Saúde, que diz respeito à pesquisa envolvendo seres humanos 5 . Além disso, foi encaminhado para o Comitê de Ética em Pesquisa da Universidade Estadual de Feira de Santana (CEP/UEFS) sob o Parecer número 2.529.234 (CAAE 74076617.3.0000.0053). 


\section{Resultados e discussão}

Este capítulo visa explanar sobre o universo da amamentação em alojamento conjunto, por meio da vivência de mulheres primíparas, através das categorias temáticas. Será desenvolvido através de três categorias: Significados da amamentação para muIheres primíparas; dificuldades para amamentação no Alojamento Conjunto; e Estratégias incentivadoras para amamentação.

\section{Significados da amamentação para mulheres primíparas}

Ao ato de amamentar sempre é atribuído aos mais diversos significados devido ao fato de que esta é uma ação e dependendo da perspectiva observada ora a ênfase está nos aspectos biológicos, ora nos demais. Existe um consenso de que o processo de amamentar é uma prática não apenas biologicamente determinada, mas também condicionada socialmente e os ganhos nos aspectos fisiológicos, psicológicos e físicos são amplamente difundidos ${ }^{6}$.

Com a consciência dos aspectos benéficos desta prática, a maioria das mães fazem a opção de amamentar seus filhos; contudo é importante não pressionar a mulher neste momento, não relegar a um segundo plano suas condições físicas e emocionais para a concretização do ato.

Um dos aspectos mais evidenciado pelas mães neste estudo foi o aleitamento materno como garantia da saúde da criança em termos de promover seu bemestar físico e emocional, relacionando-se com a formação, desenvolvimento infantil e com a resistência do organismo às doenças, o que foi referenciado por quase todas as entrevistadas.

Acho que é saúde pra ela... Porque é leite materno é saúde né? (Mãe 2)

Eu nem sei viu, acho que é um jeito de garantir a saúde do bebê. Ele se alimenta e não adoece. Num é isso? Eu acho que é só isso... (Mãe 3)

Acho que a amamentação é a parte mais importante da mulher né, e principalmente pra saúde do

bebê... prá ele crescer forte... não adoecer... bom, se desenvolver direitinho. (Mãe 4)
Como pode ser visto nos depoimentos a ênfase do aleitamento materno está nas necessidades da criança, devido ao valor incomparável do leite humano. Nesta perspectiva o aleitamento materno é representado pelas nutrizes, como indispensável à garantia do bem-estar emocional e físico da criança. O leite materno é um alimento completo, que supre as necessidades nutricionais do lactente e contribui com seu desenvolvimento, tanto físico quanto de comunicação e troca de afeto entre mãe e filho7. Assim sendo, a amamentação é pensada fundamentalmente como proteção necessária à saúde do bebê, proporcionando-lhe afeto e alimento visando seu desenvolvimento integral.

Contudo, ao assumirem o aleitamento materno como um importante controle da morbidade infantil, tomando para si toda a responsabilidade pela saúde do mesmo, sem levar em consideração o fato de que, existem outros fatores responsáveis pelo adoecimento infantil, as mulheres acabam ratificando uma prática já existente de instituir como obrigação sua, a manutenção da saúde do bebê, pela via da amamentação, desobrigando os demais atores sociais.

A Mãe 2 em seu depoimento deixou explícito este aspecto do ato de amamentar segundo o qual as mulheres, que deveriam ser as cuidadoras da prole, passam a ser responsabilizadas pela sobrevivência das crianças.

Ah... significa sei lá... significa.... não sei... Acho que é uma coisa que a gente tem que fazer, né? Amamentá, dá mama, se não ficam dizendo coisas... que a gente é inresponsável... Vi isso com uma amiga minha... Tudo que o menino tinha... era culpa dela porque não deu mama... (Mãe 02)

A amamentação tem se configurado como símbolo de cuidado despendido, responsabilidade assumida, por aquela que, a partir disso, passa a ser considerada como uma boa mãe, pois, foca sua atenção no bem-estar de sua criança. A cobrança social à mulher para que amamente seus filhos tem se respaldado nas comprovações científicas do valor do leite materno para o melhor desenvolvimento da criança em todos os seus aspectos.

Acho que é uma coisa que a gente tem que fazer, né? Se tem que fazer, a gente faz, né? Tem que dá o peito...

(Mãe 2) 
Esta fala reforça como a amamentação aparece como uma obrigação para mulher, por vezes até sem (re) pensar sobre o ato, mas simplesmente por fazê-lo. Para além desse significado social, a amamentação é um processo eivado de sentidos, entre eles estão as expressões de amor, de beleza e encantamento conforme explicitado abaixo:

É uma sensação boa... Olhar para a carinha do meu bebê... Sentir o calorzinho dele... é gostoso demais... (...) ainda não sei muito... Mas é bom... Tô muito feliz, realizada. É porque é um ser dependente da gente né,

eu me sinto muito bem em poder amamentar meu filho... (Mãe 4)

Ahhh... é um momento único assim, sei lá, não sei nem explicar de tanto amor, de tanta emoção assim dando mama ao meu filho, não tem nem explicação... É uma sensação maravilhosa! (Mãe 5)

Por outro lado, a amamentação pode ser associada à dor e à resignação sobre algo que lhe foge ao controle, como é possível observar pelos trechos abaixo:

Mas tem vez que dói muito... Aí, não tem como gostar, né? Mas, me sinto bem... Vou levando.... (Mãe 2)

É uma coisa difícil... muito difícil... e dói, dói demais... Pra falar de verdade, não acho uma coisa boa. Eu gosto dele... gosto muito... mas, dá mama né muito bom, não.

Feliz, eu sinto feliz porque ele tá se alimentando, né?

(Mãe 3)

Essas falas reforçam que a amamentação é uma arte a ser apoiada, aprendida e ensinada, não só pelos profissionais de saúde, mas pela sociedade como um todo, destacando-se o papel da famíliå .

Como é possível observar, se para algumas mães o amamentar se traduz em momentos de felicidades, para outras ele é um ato que demanda resignação e coragem, haja vista que o sacrifício está sendo feito, tanto para que o seu papel social se cumpra, como para garantir ao filho as divulgadas condições de sobrevivência oriundas do leite materno.

Essa concepção de maternidade como sacerdócio é oriunda do século XIX, mas tem sido transmitida de geração a geração. Segundo ela, ser mãe é sempre uma feliz experiência, mas que tem o seu contraponto que são os sacrifícios, as dores e sofrimentos que acabam sendo naturalizados pela mulher.

\section{Dificuldades para amamentação no alojamento conjunto}

Amamentar é uma condição natural que todos os mamíferos possuem, contudo, no ser humano, não é apenas instinto que guia o ato e para que a prática ocorra com sucesso depende de informações, reforço à decisão, aprendizado e apoio permanente, principalmente no que concerne as primigestas no puerpério imediato 9 .

O sucesso do aleitamento materno, consequente da decisão de amamentar, está sujeito a diversos fatores relacionados as condições psicobiológicas, culturais e sociais. Apesar de a importância da amamentação para o bebê, ser do conhecimento da maioria das mães e influenciar na decisão de amamentar nem sempre a amamentação ocorre de forma tranquila e surgem dificuldades que, se não sanadas a tempo, podem contribuir para o fracasso do aleitamento materno.

As dificuldades para a amamentação no AC sentidas pelas mães podem ser resultantes de diversos fatores, como despreparo durante o pré-natal, por elas não terem recebido as devidas orientações; além dos desconfortos, tanto físicos como aqueles causados pela falta de privacidade, na hora de amamentar.

É sabido que o desconhecimento da nutriz sobre os detalhes da amamentação desde o pré-natal favorece o bebê a realizar uma pega incorreta, ocorrendo uma ordenha ineficiente o que se resolveria com a melhoria da assistência à mulher no ciclo gravídico puerperal conforme preconizado por diversas iniciativas sobre o tema.

Muito embora se conheça o quanto é importante que a gestante seja acompanhada durante o pré-natal e aprenda o máximo sobre a amamentação, verificou-se com as entrevistadas que esta orientação é inexistente nas consultas durante a gravidez.

Nenhuma, realizei com uma médica e uma enfermeira do posto, mas ninguém me falou nada sobre amamentação. (Mãe 01)

Nenhuma. Malmente botavam uns aparelhos em mim... Falavam que eu tinha que comê direito (risos)... Perguntavam o que eu comia e ficavam reclamando...

De dá mama, nunca dissero nada... Nada mesmo. Eu nem gostava de ir...agente ficava muitas e muitas horas esperando pra ser atendida... (Mãe 02) 
Nenhuma...A médica... primeiro olha pra gente como se a gente fosse ET...depois vê os papéis (exames) $e$ pronto...agente já tava liberada. Não esperava pra ver se a gente ia falar ou perguntar alguma coisa. Do jeito que eu entrava, saía...Ainda bem que minha saúde é boa... senão... (Mãe 03)

A inexistência ou a orientação dada as mães no período do pré-natal é responsável pela maioria das dificuldades na amamentação e complicações mamárias enfrentadas por elas, haja vista que não recebem informações suficientes ao preparo das mamas durante a gravidez e nem são instruídas acerca dos detalhes da prática.

Se fossem colocados em prática os serviços e ações indicados pelos programas de apoio a amamentação e suporte às mães, elas estariam preparadas para enfrentar de maneira adequada as inúmeras situações que se apresentam, em especial nos primeiros dias pós-parto. Todavia, ainda são quase intransponíveis as barreiras que limitam a humanização do cuidado para as gestantes em todo o Brasil, enfatizando a distância entre o que é propalado pelas autoridades políticas e governamentais na área e o que de fato no cotidiano das pessoas.

Além da falta de orientação no pré-natal, e dos desconfortos físicos, a falta de privacidade emergiu nas falas das entrevistadas, como dificuldades da amamentação no AC.

Só não gosto muito é de ter muita gente olhando o que a gente faz... (Mãe 1)

Mas, acho que a gente num divia ficar tão imbolado... É muuuiiittaaa gente. Home, mulher, tudo junto... me sinto um pouco com vergonha sabe, fazer tudo na frente de todo mundo... Aí me sinto pior. [Quando sair] ... vai ser melhor porque eu vou ta sozinha e não vai ter mais ninguém... pra ficar vendo tudo que a gente ta fazendo. Se não fosse purisso e pelo calor... Mas pelo cuidado, tá sendo bom, eu pensava que ia ser bom... Que calor... Meu Deus. (Mãe 02)

Aqui... vejo umas coisas que não acho boas... É muita gente no mesmo lugar... isso dá um pouco de vergonha... a gente fica sem jeito... A outra coisa é o calor... ta demais... porque está sem ar. (Mãe 03)

é muita gente junta, muito calor e todo mundo vendo o que a gente ta fazendo... fico um pouco... acanhada. Normal ... né? (Mãe 4)
Para mim... a experiência aqui não está sendo agradável não, sinceramente não gosto muito não, porque eu preciso de um conforto pra mim dá mama a ele... aqui entra todo mundo, sai toda hora e assim eu fico um pouco envergonhada dando mama a ele, sei lá, fico muito assim... sabe... muito envergonhada, exposta. (Mãe 05)

Outras pesquisas encontraram o mesmo resultado desta, no que diz respeito à insatisfação das mães com a falta de privacidade, a exemplo da realizada por Silva e colaboradores ${ }^{10}$ em um estudo realizado com 14 usuárias que se encontravam no período do pós-parto imediato, visando conhecer a percepção delas sobre a assistência em uma maternidade no Nordeste brasileiro que implantou o PHPN.

É certo que o alojamento conjunto já deixa explícito a ideia de coletividade, de convivência, mas é muito importante que cada puérpera e familiares um tenha um pouco de privacidade o que transmitira uma maior sensação de conforto, de acolhimento. Isto certamente serviria de reforço às ações levadas a termo para estimular a amamentação.

\section{Estratégias incentivadoras para amamentação}

$\mathrm{Na}$ contramão das dificuldades vivenciadas pelas puérperas para a prática da amamentação no $A C$, emergem as ações desenvolvidas para potencializar a amamentação e percebemos que tem surtido efeitos positivos, haja vista que que cada vez mais mulheres decidem amamentar e muitas mostram-se satisfeitas com a sensação de acolhimento que sentem pelo tratamento recebido no alojamento conjunto.

O trabalho desenvolvido pelos profissionais da saúde faz diferença na estrutura emocional da mulher durante o pós-parto, assim como na técnica e segurança para a referida prática, o que certamente vai contribuir para que a amamentação se dê de uma forma tranquila e prazerosa ou, pelo menos, sem os traumas provocados pelo desconhecimento da técnica de alimentação.

A orientação dada às puérperas acerca da técnica de amamentação minimiza significativamente os problemas que as nutrizes poderiam enfrentar, transmitindo-Ihes confiança para um aleitamento materno tranquilo potencializando a sensação de bem-estar pelo tratamento recebido. 
Respondendo acerca do tipo de orientações recebidas no AC, as participantes assim responderam:

Eles ensina a pegar botar ele no peito, se ele tiver dormindo sempre pegar ele, não deixar ele dormir demais, botar no peito pra poder mamar mesmo se ele estiver dormindo, tem que sempre acordar ele pra mamar, por mais que não esteja saindo leite para estimular. Ensina como pegar no peito, como botar o bico todo do peito pra não machucar. Sempre beber agua depois de amamentar... Sempre tem alguém cuidando... E isso faz agente se sentir segura... E ajuda a cuidar do bebê, direitinho. (Mãe 01)

Me ensinaro como é a posição de mamar, que é pra pegar botar aqui no braço e botar aqui no peito pra ela pegar. (Mãe 02)

Recebi orientação... Aprendi muita coisa que era novidade, porque eu não sabia mesmo, as coisas da amamentação, que tem um jeito certo do bebê pegar o seio, que tem de limpar sempre o bico... Como é melhor poder dar mama ao menino... (Mãe 03)

Como se pode observar, a ênfase das orientações recebidas pelas puérperas esteve na pega correta, postura adequada para amamentar, informações indispensáveis para que o aleitamento materno seja iniciado e tenha continuidade de forma profícua. Estes cuidados que foram dispensados pelos profissionais com quem as mães mantiveram contato durante internamento no AC.

Desse modo, o aconselhamento, a informação e comunicação constituem-se estratégias do enfermeiro no manejo clínico da amamentação. Além disso, o desempenho desse profissional é de grande importância para o apoio e promoção do aleitamento materno, permitindo que efetivar-se intervenções nas complicações, confusos e medo das nutrizes, assim dificultando o desmame precoce ${ }^{11}$.

Assim, reforça-se a importância da atuação da enfermeira para o sucesso da prática da amamentação e que, no caso das entrevistadas desta pesquisa, tratavam-se somente de mulheres primíparas, que tinham sua primeira experiência em amamentar. Desta forma, torna-se proporcional o suporte, as orientações desde o puerpério imediato para que amamentação continue após a alta hospitalar com sucesso e sem tabus, medos ou inseguranças; evitando inclusive o desmame precoce.
Com relação ao membro da equipe que forneceu orientação sobre amamentação no $A C$, as puérperas apontam diferentes sujeitos, tendo destaque para as enfermeiras:

As enfermeiras, daqui que me orientou, achei bom, (...) Nem pensava que ia ser assim. Achei que a gente ia ter que se virar, que ninguém ia ligar pra gente, não. (Mãe

Onde, aqui? Bom aqui tem os médicos, as enfermeiras

(Mãe 2)

Aqui? As enfermeiras, só. (Mãe 03)

Aqui, foi a Enfermeira e a pessoa do banco de leite... Essa me disse que eu tenho que dar mama toda hora que o bebê quiser, que assim o leite vai saindo... cada vez mais e eu tô fazendo. (Mãe 04)

Conforme explicitado foi o profissional de enfermagem quem esteve mais presente no atendimento às mães para prática de amamentação, cuidando-as por meio das orientações, transmitindo-lhes segurança e informações necessárias.

O profissional de enfermagem é o que mais se relaciona com a mãe durante a gravidez e após a mesma, tem um papel muito importante nos programas de educação em saúde durante o pré-natal. Assim, o enfermeiro deve preparar a gestante para o aleitamento, para que quando o bebê nascer, o processo de adaptação da mesma ao aleitamento seja facilitado e tranquilo, esclarecendo todas as dúvidas e evitando possíveis complicações ${ }^{12}$.

\section{Conclusão}

Ressalta-se que, em cada momento da história, a amamentação assume significados distintos que estão subjacentes no imaginário das mães; pois, é um processo sociocultural e que tem relação direta com valores que cada mãe e sua família atribuem à amamentação.

Para as participantes desta pesquisa, o principal significado da amamentação, está no fato de constituirse um ato de amor, prazeroso, que traz encantamento e felicidade, evidenciando também o aleitamento materno como promoção da saúde e crescimento 
da criança; de seu bem-estar físico e emocional, prevenção de doenças e desenvolvimento do vínculo de amor entre mãe e filho.

No que se refere à visão das mães sobre as dificuldades da amamentação pode-se afirmar que as principais foram provocadas pela falta de orientação no pré-natal. Os problemas surgidos foram aqueles relacionados ao manejo inadequado da amamentação, conhecimento prévio que deveria ser adquirido no período gestacional. Além destas relativas aos aspectos físicos, a maioria das nutrizes se referiram à falta de privacidade como uma das dificuldades para amamentar no AC devido ao constrangimento provocado por ter sempre muita gente no espaço, na hora de amamentar ou fazer outros procedimentos relativos à amamentação, em que houvessem a exposição das mamas.

No que se refere às facilidades ou estratégias incentivadoras para amamentação, estiveram presentes o repasse de orientações acerca das técnicas adequadas de aleitamento e o apoio para que a amamentação acontece precocemente.

Conclui-se que as práticas da amamentação sofrem diversas influencias, sendo; além disso, ressalta-se que é fundamental o preparo profissional para incentivar que a amamentação acontece nas primeiras horas pós-parto, de maneira processual, sem desgaste físico e emocional, seja para mãe e o bebê. Chama atenção para que as informações relativas à amamentação iniciem durante o pré-natal e tenham sequência no parto e puericultura, afim de obter resultados mais positivos quanto a realização dessa prática no Alojamento Conjunto e na continuidade no domicílio.

\section{Contribuições dos autores}

Todas as autoras contribuíram igualmente na concepção e elaboração do trabalho.

\section{Conflitos de interesses}

Nenhum conflito financeiro, legal ou político envolvendo terceiros (governo, empresas e fundações privadas, etc.) foi declarado para nenhum aspecto do trabalho submetido (incluindo, mas não se limitando a subvenções e financiamentos, participação em conselho consultivo, desenho de estudo, preparação de manuscrito, análise estatística, etc.).

\section{Referências}

1. Amaral LJX, Sales SS, Carvalho DPSRP, Cruz GKP, Azevedo IC, Júnior MAF. Fatores que influenciam na interrupção do aleitamento materno exclusivo em nutrizes. Rev Gaúcha Enferm. 2015;36(esp):127-34. doi: 10.1590/1983-1447.2015.esp.56676

2. Mariani Neto C. Manual de aleitamento materno. 3ed. São Paulo: Federação Brasileira das Associações de Ginecologia e Obstetrícia; 2015.

3. Figueiredo LR, Mendes KA, Matozo AMS, Santos AG, Abreu GR. Aplicação do processo de enfermagem em alojamento conjunto: relato de experiência. PECIBES. 2018;4(2):49-101.

4. Bardin, L. Análise de conteúdo. São Paulo: Edições 70; 2011.

5. Ministério da Saúde. Conselho Nacional de Saúde. Resolução 466, de 12 de dezembro de 2012. Diretrizes e Normas Regulamentadoras de pesquisas envolvendo seres humanos [Internet]. 2012. Disponível em: <http://bvsms.saude.gov.br/bvs/ saudelegis/cns/2013/res0466_12_12_2012.html>

6. Santos TMC, Santos MC, Menezes OAC. Fatores associados à ausência de aleitamento materno na alta hospitalar em uma maternidade pública de Maceió, Alagoas, Brasil. Ciênc Saúde Coletiva. 2018;23(11):3547-3556. doi: 10.1590/1413$\underline{812320182311.25542016}$

7. Hernandes TA, Fujinami AN, Raimundo EC, Cardoso CP, Higa EFR, Lazarini CA. Significado e dificuldades da amamentação: Representação Social das Mães. Rev Psicol Divers Saúde. 2017;6(4):247-25. doi: 10.17267/2317-3394rpds.v6i4.1692

8. Batista KRA, Farias MCAD, Melo WSN. Influência da assistência de enfermagem na prática da amamentação no puerpério imediato. Saúde em Debate. 2013;37(96):130-138. doi: $10.1590 /$ S0103-11042013000100015

9. Fialho FA, Lopes AM, Dias IMAV, Salvador M. Fatores associados ao desmame precoce no aleitamento materno. Rev Cuid. 2014;5(1):670-8.

10. Silva LNM, Silveira APKF, Barreto JM, Góis ARP, Lima PCP, Santos MAS et al. PHPN e a percepção das usuárias de uma maternidade do Nordeste Brasileiro. In: Convibra - Congresso On line; 2016.

11. Oliveira FKF, Fraga ASB, Hora AB, Dias JJ, Santos FLLSM. Dificuldades e estratégias para o aleitamento materno prolongado sob a visão do enfermeiro. Universidade Tiradentes. 2017;9(12):1-4.

12. Uyeda M, Martinez LCB. Os aspectos nutricionais e da enfermagem no processo de amamentação. Saúde em Foco. 2015;7(1):161-170. 